\title{
Baby sleep incidental aspiration - case report
}

MAGDALENA POTEMPA-JEZIOROWSKA ${ }^{1,2, A, B, E, F}$

ORCID ID: 0000-0002-7655-0151

${ }^{1}$ Chair and Department of Descriptive and Topographic Anatomy, Medical University of Silesia, School of Medicine with Division of Dentistry in Zabrze, Poland

2 Pediatric Ward, Multidisciplinary District Hospital in Tarnowskie Gory, Poland

A - Study Design, B - Data Collection, C - Statistical Analysis, D - Data Interpretation, E - Manuscript Preparation, F - Literature Search, G - Funds Collection

Summary Aspiration pneumonia usually occurs among infants with co-existing medical states like neurological, abnormalities of deglutition, gastroesophageal reflux or congenital malformations. In rare cases, aspiration can also be accidental among healthy children. In this group of patients, aspiration pneumonia develops less frequently because of properly working protective mechanisms. The author presents an 8-week-old baby with no-comorbidities that aspirated during sleep. Due to the Breathing Movement Monitor alarm and proper observer reaction, the baby was saved. Observation of aspiration pneumonia was negative. The paper also presents some theory about apnea and aspiration pneumonia in children.

Key words: airway obstruction, apnea, pneumonia.

M. Potempa-Jeziorowska. Baby sleep incidental aspiration - case report. Fam Med Prim Care Rev 2020; 22(4): 349-352, doi: https:// doi.org/10.5114/fmpcr.2020.100450.

\section{Case report}

A nearly 8-week-old baby girl was admitted to the district hospital, transported by emergency services, after suspicion of sleep aspiration. Anamnesis revealed that baby was fed (starting milk formula) about half an hour before aspiration. As was routine, just after feeding, the mother put the baby up for about 15-20 minutes until the baby falls asleep. She then lay the baby on one side and turned on the breathing monitor. After some minutes, the monitor sounded an alarm. According to the mother, the baby was pale and unconscious, and muscle tone was decreased. The mother took the child in her arm in a head down position and started to hit the baby in the interscapular area. She did this a few times with baby in her arm in a head down position. During this time, the father called the emergency services. After a few minutes, the baby cried. The mother looked into baby's oral cavity and saw a small amount of partly digested milk. Emergency services arrived and took the conscious baby to the hospital. On admission, the baby was cardiorespiratory efficient. A physical examination revealed: central cyanosis (around the mouth) and bilateral auscultatory whirring. There were no other abnormalities in the examination. The body mass was $4.4 \mathrm{~kg}$. The past medical history, i.e. the mother's medical history and pregnancy, was without abnormalities. Perinatal time was physiological, with natural labor in the $41^{\text {st }}$ week of pregnancy, with nitrous oxide inhalation anesthesia. The baby's Apgar score was 10/10/10/10. Birth weight was $3,440 \mathrm{~g}$. Vitamin $\mathrm{K}(1 \mathrm{mg})$ was administered intramuscular within 24 hours after birth, as well as obligatory vaccinations. The baby had skin to skin contant with mother and was in rooming-in unit care. The baby was breastfeeding from the beginning. On the third day, body mass decreased about $10 \%$, and the bilirubin level was $8 \mathrm{mg} \%$. Because of good general condition on the same day, the baby was discharged from the hospital. After 1 month, breastfeeding was insufficient and infant formula milk was included in the baby's diet. Until the day of aspiration, the baby had proper weight gain. The parents did not report any medical problems with the baby before. Admission blood tests revealed decreased saturation $(92 \%)$ and oxygen partial pressure $(56.6 \mathrm{~mm} \mathrm{Hg})$. All admission laboratory testing parameters are presented in Table 1. In therapy, a broad-spectrum antibiotic (Cefuroxim) was used systemicly. Sup-

\begin{tabular}{|c|c|c|c|c|c|c|c|c|}
\hline Blood count & $\begin{array}{l}\text { RBC } \\
\left(* 10^{\wedge} 6 / \text { uL }\right)\end{array}$ & $\begin{array}{l}\text { HGB } \\
(\mathrm{g} / \mathrm{L})\end{array}$ & $\begin{array}{l}\text { PCV } \\
(\%)\end{array}$ & $\begin{array}{l}\text { WBC } \\
\left(* 10^{\wedge} 3 / \mathrm{uL}\right)\end{array}$ & $\begin{array}{l}\text { PLT } \\
\left(* 10^{\wedge} 3 / \text { uL) }\right.\end{array}$ & $\begin{array}{l}\text { MCV } \\
\text { (fil) }\end{array}$ & $\begin{array}{l}\text { MCH } \\
\text { (pg) }\end{array}$ & $\begin{array}{l}\mathrm{MCHC} \\
(\mathrm{g} / \mathrm{dL})\end{array}$ \\
\hline & 4.17 & 12.9 & 36.0 & 17.65 & 606 & 86.3 & 30.9 & 35.8 \\
\hline \multirow[t]{4}{*}{$\begin{array}{l}\text { Arterial blood } \\
\text { gas (ABG) }\end{array}$} & $\mathrm{pH}$ & $\begin{array}{l}\mathrm{pCO}_{2} \\
(\mathrm{~mm} \mathrm{Hg})\end{array}$ & $\begin{array}{l}\mathrm{pO}_{2} \\
(\mathrm{~mm} \mathrm{Hg})\end{array}$ & $\begin{array}{l}\text { SatO }_{2} \\
(\%)\end{array}$ & $\begin{array}{l}\text { BE } \\
(\mathrm{mmol} / \mathrm{L})\end{array}$ & $\begin{array}{l}\mathrm{HCO}_{3} \\
(\mathrm{mmol} / \mathrm{L})\end{array}$ & $\begin{array}{l}\mathrm{Na}+ \\
(\mathrm{mmol} / \mathrm{L})\end{array}$ & $\begin{array}{l}\mathrm{Ka}+ \\
\text { (mmol/L) }\end{array}$ \\
\hline & 7.42 & 37.2 & 56.6 & 91.2 & -0.2 & 24.0 & 138 & 5.32 \\
\hline & \begin{tabular}{|l} 
Glucose \\
(mg/dL)
\end{tabular} & $\begin{array}{l}\text { CRP } \\
\text { (mg/L) }\end{array}$ & \begin{tabular}{|l} 
Lactates \\
(mmol/L)
\end{tabular} & & & & & \\
\hline & 94 & 0.6 & 1.5 & & & & & \\
\hline \multirow[t]{2}{*}{ Urinalysis } & \begin{tabular}{|l} 
Specific \\
gravity
\end{tabular} & $\mathrm{pH}$ & $\begin{array}{l}\text { Protein } \\
\text { (mg/dL) }\end{array}$ & $\begin{array}{l}\text { Ketone } \\
\text { (mg/dL) }\end{array}$ & $\begin{array}{l}\text { Glucose } \\
\text { (mg/dL) }\end{array}$ & Urobilinogen & \multicolumn{2}{|c|}{ Urine microscopy } \\
\hline & 1.010 & 7.0 & 25 & negative & negative & normal & \multicolumn{2}{|c|}{$\begin{array}{l}\text { WBC 1-3 } \\
\text { Epithelial cells occasional; } \\
\text { Bacteria occasional }\end{array}$} \\
\hline
\end{tabular}

RBC - red blood count, HGB - hemoglobin, PCV - packed cell volume, WBC - white blood count, PLT - platelets count, MCV - mean corpuscular hemoglobin, MCHC - mean corpuscular hemoglobin concentration. 
plemental oxygen was administered during the $1^{\text {st }}$ day of hospitalization. Over the next few days, oxygen supplementation was just intermittent because of a lack of the baby's alarming syndromes. Cyanosis had withdrawn. Auscultating changes retracted gradually, and there was no cough. The baby was feeding normally, and weight gain was controlled systematically. An abdomen ultrasound and neonatal cranial ultrasound were carried out, and normal findings were obtained. An EEG test did not reveal any disorders. A chest Xray was done on the $3^{\text {rd }}$ day and revealed normal findings. Because of a periodically auscultated systolic extra heart sound, cardiological consultation was performed. It revealed an atrial septal defect (ASD) with no hemodynamic significant effect. On the $5^{\text {th }}$ day, when antibiotic therapy had finished, the baby was discharged from the hospital in good physical condition. Body mass was $4.54 \mathrm{~kg}$. Observation of aspiration pneumonia was negative.

\section{Discussion}

In the pediatric group, aspiration commonly occurs because of deglutition abnormality or gastroesophageal reflux. It can present as accidental aspiration. Opposite to gaging, which is defined as the accidental, common and non-serious presence of a foreign body in the upper respiratory track, aspiration results in the redistribution of a foreign body into the lower respiratory track. It is more dangerous and is clinically linked with many severe consequences. In the described case report, because of milk aspiration, there was a cessation of breathing, which caused apnea. Infantile apnea affects males and females in equal numbers and occurs in children less than 1 year old; however, the true prevalence of apnea in infants in unknown. It is mainly characteristic for preterm infants, whose incidence of apnea is inversely related to gestational age. Considering time of birth apnea can be divided into prematurity apnea (when infant is younger than 37 ' weeks gestational age) and apnea of infancy when deals with full term baby. The etiology of apnea in infants is broad and varies according to the baby's age and evoking mechanism [1]. Clinically apnea is defined as lasting at least 20 seconds. Brief periods of apnea that occur in short cycles of $5 \mathrm{sec}-$ onds to 10 seconds are not pathological [2]. Any apnea above 15 or 20 seconds is always pathological. Breathing monitor alarms when apnea lasts above 20 seconds. In the described case, the baby had term birth without any co-mobilities, and the mother had the monitor as prevention. She did not indicate any other reasons to have the monitor. The parents also did not have any earlier experience with baby aspiration or even SIDS (Sleep Infant Death Syndrome). In the described report, the baby developed apnea in the course of regurgitation. This is a common symptom of gastric reflux. Clinically it can be asymptomatic or manifest just as burping after feeding. The mechanism of apnea in the course of gastric reflux is probably mixed. It is a period of central apnea, typically followed by obstruction or narrowing of the airway and inadequate respiratory efforts to maintain ventilation. It is the most frequent type among preterm infants, but it can occur through other triggering factors like gastroesophageal reflux or respiratory infectious disease (pertussis, bronchiolitis). Apnea can also be central or separately obstructive (Figure 1) [3, 4].

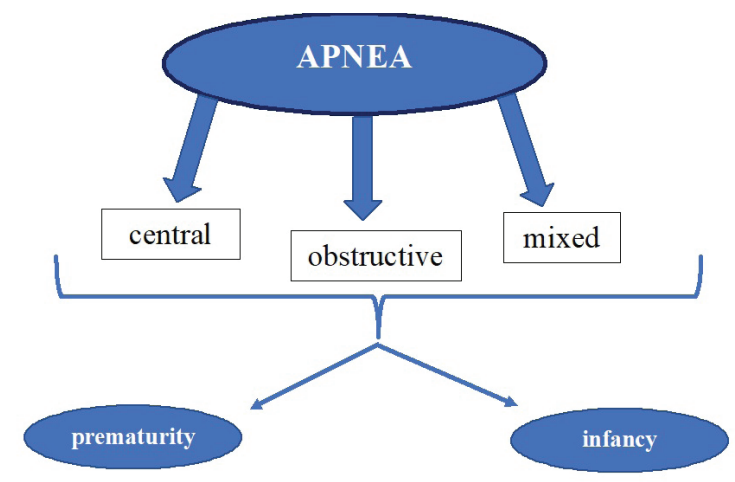

Figure 1. Schematic division of apnea
The sudden absence of breathing and loss of responsiveness can be associated with a group of symptoms known as a brief resolved unexplained event (BRUE). According to guidelines, BRUE determines an event occurring in an infant when the observer reports a sudden, brief and then resolved episode of $\geq 1$ of the following: cyanosis or pallor; absent, decreased, or irregular breathing; marked change in muscle tone and altered level of responsiveness. A BRUE diagnosis is confirmed when there is no explanation for a qualifying event after conducting an appropriate history and physical examination [5].

It is also worth mentioning SIDS, which, on the first sight, seems to be very similar to above states. SIDS is the sudden unexpected death of an apparently healthy infant without any comorbidities, younger than 12 months of age, whose cause of death remains unknown despite a thorough investigation of the death, a review of the clinical history and an autopsy. SIDS is a subcategory of SUID (Sudden Unexpected Infant Death), which defines unexpected death in infancy because of known or unknown reasons. In recent years, according to data coming from United States, the rate of SIDS has plateaued in spite of ongoing educational efforts promoting safe sleep and other risk reduction measures. To help SIDS prevention, the American Academy of Pediatrics guidelines focus on a safe sleeping environment, i.e. supine positioning, the use of a firm sleep surface, room-sharing without bed-sharing and the avoidance of soft bedding and overheating. The avoidance of smoke exposure (pre- and postnatal), alcohol and illicit drugs, breastfeeding, vaccination and use of a pacifier [6, 7] are also included. In the described case report, the BLS procedure was carried out. The mother had done it correctly, which is why the baby was saved. There is a paucity of data evaluating the correctness of basic life support procedures. In the study by Barry et al., a learning program educating and providing basic life support in the case of a baby choking was evaluated. The program, coupled with the use of a novel infant pillow mannequin (during antenatal education classes), was assessed to check whether low-cost intervention with the potential for widespread application could enable training in the event of an infant choking. The results showed that more than $90 \%$ of participants demonstrated correct positioning of the infant in the event of choking. They correctly identified the correct ratio of chest compressions to breaths and conducted chest compressions to the required depth [8].

\section{Aspiration pneumonia}

Aspiration pneumonia is an important cause of serious morbidity, particularly among children with chronic medical conditions $[9,10]$. It results from the passage of alimentary track contents into the lower respiratory tract. In normal condition, the lower respiratory track is sterile. Patient clinical stage and development of lung changes depend on the nature and amount of aspirated material, as well as patient natural protective mechanisms, like ciliary clearance and cough. The causative microorganisms in aspiration pneumonia are basically thought to be bacteria residing in the oral cavity, such as pneumococcus, Haemophilus influenzae, Staphylococcus aureus and anaerobes [11,12]. There are 3 types of aspiration syndrome in regard to inoculum, which depends on the pathogenesis of the lung state: (1) chemical; (2) oropharyngeal secretion aspiration and (3) aspiration of inert fluids and particular matter. Chemical aspiration syndrome is commonly associated with Mendelson's syndrome, which is defined as a chemical injury due to inhalation of sterile gastric contents [13]. Pulmonary aspiration is a rare but known risk of general anesthesia. A study by Tan and Lee evaluated $0.02 \%$ incidence of pulmonary aspiration among a pediatric group undergoing general anesthesia. The majority of children who aspirated were 3-12 years old with no co-morbidities. None of them had any history of pulmonary aspiration [14]. Every co-occurrence of chronic medical condition increases the probability to develop pneumonia. The described infant was without any medical disturbances and did not belong to any risk group. In healthy children, the risk of aspiration pneumonia development is lower than among patients with some disorders, but when aspiration occurs, the child should be 
observed by medical staff and hospitalized. Aspiration pneumonia risk factors are neurological disorders (impairment of neuromuscular coordination, changes in muscle tone, cerebral palsy, meningitis, myasthenia gravis, birth asphyxia and preterm birth), genetic diseases (e.g. Spinal Muscle Atrophy, Down Syndrome), altered consciousness (e.g. seizures, drug overdose, cerebrovascular accidents, head trauma, general anesthesia), anatomic malformations (e.g. alimentary track, cardiovascular system and respiratory track malformations, cranial malformations) and disruption of normal defense barriers (e.g. naso-gastric tube, tracheostomy) [15, 16]. There is a paucity of data characterizing children hospitalized with aspiration pneumonia. The study by Karim et al. described 107 hospitalized children aged 0-15 (mean age 23-27 months) suffered from aspiration pneumonia. According to the results, the three most frequent aspiration causes were: accidental ingestion (37.4\%), altered consciousness $(34.6 \%)$ and neurological diseases (29\%). Anatomic disorders, mechanical disruption and physiologic disorders each occurred in $7.5 \%$ of the study population. Of the $34.6 \%$ of patients with altered consciousness, $22.4 \%$ had a history of seizures, and $5.6 \%$ suffered from birth asphyxia. Among neurologic disorders, $10 \%$ were delivered preterm, and $9 \%$ had cerebral palsy. Milk was the most common aspirated material (31.8\%), and slightly less was kerosene oil (21.5\%) and oral secretions (19.6\%). All were organic in nature. Chemical pneumonia was the most common form of pneumonitis (52.1\%). Nearly one-third showed inert fluids/particulate matter (27.4\%). This study showed a $17.8 \%$ mortality rate among children suffering from aspiration pneumonia [17]. There is a lack of new data comparing this value. Studies from 1988 and 1973 noted a wide range of mortality, from $7.5 \%$ to $62 \%$, respectively $[18,19]$. In a study published in 2016, a comparative analysis of some clinical parameters between children hospitalized with a diagnosis of aspiration pneumonia and community-acquired pneumonia (CAP) was developed. The necessary data obtained for the study focused on a 6-year time period from 2009-2014. The results showed that aspiration pneumonia occured nearly 10 times more rarely than CAP. Compared with children with CAP, children with aspiration pneumonia were younger and more likely to have an associated complex chronic disease. Those with aspiration pneumonia had longer hospitalization periods, higher rates of ICU (Intensive Care Unit) admission and higher 30-day readmission rates. As a consequence, the median cost for hospitalization was 2.4 times higher for children with aspiration pneumonia than for children with CAP [10]. In clinical practice, it is very essential to remember about congenital malformations, which narrow the esophageal lumen. These can manifest as chronic and recurrent pneumonia, bronchitis or even cough. Symptoms can come from alimentary track, e.g. gastroesophageal reflux. Vessels malformations like compression by double aortic arch is also characteristic to cause aspiration [20].

Aspiration of oily substances into the respiratory system can induce exogenous lipoid pneumonia (ELP). This is a very rare cause of inflammation within the respiratory track and was first mentioned by Laughlin in 1925 [21]. Particles of oily substances (oily intranasal, oral drops, Vaseline, high-fat milk, egg yolk) get into the lower parts of the respiratory tract. An incorrect position during feeding (horizontal), cleft palate and swallow disorders enhance the possibility to aspiration. Oil inhibits the cough reflex and ciliary motion and si- lently reaches the alveoli. It leads to enzymatic decay of lung tissue and the release of fatty acids, which destroy lung tissue and cause necrotizing bronchopneumonia. Lipid-laden macrophages and giant cells in the alveolar lumen are characteristic for ELP [21, 22]. Clinical course is usually unpromising particularly among infants and toddlers [17]. The aspiration of mineral oil is the most common cause of lipoid pneumonia in children [23]. Buda et al. reported on the clinical case of a 3-year-old girl diagnosed with lipoid pneumonia who had been on a 1 year ketogenic diet. The girl suffered from intractable epilepsy due to congenital cytomegalovirus infection and had pharmacological treatment adequate to the diagnosis. During the ketogenic diet, she had a seizure-free period. She was admitted to the hospital due to fever and dyspnea lasting two months. General weakness and marked weight loss were also noticed. There were no other signs of upper respiratory infection (cough, rhinitis). Laboratory tests revealed elevated white blood cells $19 \times 10^{9} / \mathrm{I}$, C-reactive protein (CRP) $12.27 \mathrm{mg} / \mathrm{dl}$ (normal range $<0.5 \mathrm{mg} / \mathrm{dl}$ ), ferritin $-506 \mathrm{ng} / \mathrm{ml}$ and an erythrocyte sedimentation rate (ESR) of $110 \mathrm{~mm} /$ hour. Investigations also disclosed decreased hemoglobin of $10.2 \mathrm{~g} / \mathrm{dl}$, hypoalbuminemia $(16 \mathrm{~g} / \mathrm{l})$, ketone bodies in urine and negative blood cultures. The chest $\mathrm{X}$-ray and computed tomography (CT) scan showed massive and diffuse parenchymal infiltration of the right lung, atelectasis of the left dorsal basal lung segment and enlarged paratracheal and hilar lymph nodes. In therapy, wide-spectrum antibiotics were applied, but clinical improvement was very poor. ELP suspicion was estimated, and bronchoscopy with material from bronchoalveolar lavage (BAL) analysis was performed. Next, the ketogenic diet was discontinued. BAL analysis revealed that the macrophages included deposits showing positive Sudan staining, suggesting the presence of fat droplets. On this basis, diagnosis of lipoid pneumonia was confirmed. Anti-inflammatory treatment with the use of glucocorticosteroids $(1-2 \mathrm{mg} / \mathrm{kg} /$ day) was started, initially parenterally then orally. After 2 weeks of treatment, significant clinical improvement was observed [24].

\section{Conclusions}

Sleep aspiration among children is an issue concerning broad pathogenesis and etiology. In the described case report, aspiration was due to feeding. Interestingly, the infant did not present any symptoms of gastroesophageal reflux beforehand. Among healthy full-term babies, this is rarity. Author pay a special attention to exemplary observer reaction, who has correctly done basic life support procedure. Dissemination of pediatric basic life support skills, while recommended, is not done routinely for pregnant women and their partners within the maternity services. It is similar with SIDS prevention guidelines when discharging from the hospital. It is also very important to encourage parents to have a room-sharing system, with the infant on a separate sleep surface. Breathing monitor however not recommended, in described case was very valuable. Most important seems to be gastric reflux prevention methods, a safe sleeping environment and basic life support skills. In clinical practice, it is very essential among pediatricians, neonatologists and family physicians to properly educate parents in case of accidental aspiration, as well as encourage a safe sleeping environment.

Source of funding: This work was funded from the authors' own resources.

Conflicts of interest: The authors declare no conflicts of interest.

\section{References}

1. Regenbogen E, Zhang S, Yang J et al. Epidemiological trends among preterm infants with apnea. A twelve-year database review. Int J Pediatr Otorhinolaryngol 2018; 107: 86-92.

2. Ginsburg D, Maken K, Deming D, et al. Etiologies of apnea of infancy. Pediatr Pulmonol 2020, doi: 10.1002/ppul.24770.

3. Kondamudi NP, Wilt AS. Infant apnea. Treasure Island (FL): StatPearls Publishing; 2020.

4. Ramos-Fernández JM, Sánchez-Pérez M, Sánchez-González JM, et al. Apnea in infants hospitalized with pertussis: incidence and gestational smoking association. Pediatr Int 2018; 60(10): 943-947.

5. Tieder JS, Bonkowsky JL, Etzel RA, et al. Brief resolved unexplained events (formerly apparent life-threatening events) and evaluation of lower-risk infants. Pediatrics 2016; 137(5): pii: e20160590, doi: 10.1542/peds.2016-0590. 
6. Moon R, Feldman-Winter L, Goodstein MH, et al. Task force on sudden infant death syndrome. SIDS and other sleep-related infant deaths: updated 2016. Recommendations for a safe infant sleeping environment. Pediatrics 2016; 138(5): e20162938, doi: 10.1542/ peds.2016-2938.

7. Hauck FR, Tanabe KO. Beyond "Back to Sleep": ways to further reduce the risk of sudden infant death syndrome. Pediatr Ann 2017; 46(8): e284-e290.

8. Barry M, Dixon M, Armstrong C, et al. The pillow project, infant choking, and basic life support training for prospective parents: a lowcost intervention for widespread application. J Perinat Neonatal Nurs 2019; 33(3): 260-267.

9. DiBardino DM, Wunderink RG. Aspiration pneumonia: a review of modern trends. J Crit Care 2015; 30(1): 40-48.

10. Hirsch AW, Monuteaux MC, Fruchtman G, et al. Characteristics of children hospitalized with aspiration pneumonia. Hospital Pediatrics 2016; 6(11): 659-666.

11. El Solh AA, Pietrantoni C, Bhat A, et al. Microbiology of severe aspiration pneumonia in institutionalized elderly. Am J Respir Crit Care Med 2003; 167: 1650-1654.

12. Higa F, Saito A. Pathogenic bacteria in aspiration pneumonia. Geriatr Med 1997; 35: 153-156.

13. Russin SJ, Adler AG. Pulmonary aspiration. The three syndromes. Postgrad Med 1989; 85(1): 155-161.

14. Tan Z, Lee SY. Pulmonary aspiration under GA: a 13-year audit in a tertiary pediatric unit. Paediatr Anaesth 2016; 26(5): 547-552.

15. Weir K, McMahon S, Barry L, et al. Oropharyngeal aspiration and pneumonia in children. Pediatr Pulmonol 2007; 42(11): $1024-1031$.

16. Thomson J, Hall M, Ambroggio L, et al. Aspiration and non-aspiration pneumonia in hospitalized children with neurologic impairment. Pediatrics 2016; 137(2): e20151612, doi: 10.1542/peds.2015-1612.

17. Karim RM, Momin IA, Lalani II, et al. Aspiration pneumonia in pediatric age group: etiology, predisposing factors and clinical outcome. J Pak Med Assoc 1999; 49(4): 105-108.

18. Hickling KG, Howard R. A retrospective survey of treatment and mortality in aspiration pneumonia. Intensive Care Med 1988; 14(6): 617-622.

19. Cameron JL, Mitchell WH, Zuidema GD. Aspiration pneumonia: clinical outcome following documented aspiration. Arch Surg 1973; 106(1): 49-52.

20. Oliveira GA, Pessanha LB, Guerra LFA, et al. Aspiration pneumonia in children: an iconographic essay. Radiol Bras 2015; 48(6): 391-395.

21. Baron S, Haramati L, Rivera V. Radiological and clinical findings acute and chronic exogenous lipoid pneumonia. J Thorax Imaging 2003; 18(4): 217-224.

22. Krychniak-Soszka A, Lewandowska K, Skorupa W, et al. Exogenous lipoid pneumonia - a report of four cases. Pneumonol Alerg Pol 2005; 73: 182-188.

23. Zanetti G, Marchiori E, Gasparetto TD, et al. Lipoid pneumonia in children following aspiration of mineral oil used in the treatment of constipation: high-resolution CT findings in 17 patients. Pediatr Radiol 2007; 37(11): 1135-1139.

24. Buda P, Wieteska-Klimczak A, Własienko A, et al. Lipoid pneumonia - a case of refractory pneumonia in a child treated with ketogenic diet. Pneumonol Alergol Pol 2013; 81(5): 448-452.

Tables: 1

Figures: 1

References: 24

Received: 11.05 .2020

Reviewed: 18.05 .2020

Accepted: 6.08 .2020

Address for correspondence:

Magdalena Potempa-Jeziorowska, MD

Katedra i Zakład Anatomii Opisowej i Topograficznej

Wydział Nauk Medycznych w Zabrzu

Śląski Uniwersytet Medyczny w Katowicach

ul. Jordana 19

41-808 Zabrze

Polska

Tel.: +48 502 730-040

E-mail: magdalenapotempa@o2.pl 